\title{
Preclinical And Clinical Development Of Oncolytic Adenovirus For The Treatment Of Malignant Glioma
}

This article was published in the following Dove Press journal: Oncolytic Virotherapy

\author{
Juri Kiyokawa \\ Hiroaki Wakimoto \\ Department of Neurosurgery, \\ Massachusetts General Hospital, Harvard \\ Medical School, Boston, MA, USA
}

\begin{abstract}
Replication conditional oncolytic human adenovirus has long been considered a promising biological therapeutic to target high-grade gliomas (HGG), a group of essentially lethal primary brain cancer. The last decade has witnessed initiation and some completion of a number of Phase I and II clinical investigations of oncolytic adenovirus for HGG in the US and Europe. Results of these trials in patients are pivotal for not only federal approval but also filling an existing knowledge gap that primarily derives from the stark differences in permissivity to human adenovirus between humans and preclinical mouse models. DNX2401 (Delta-24-RGD), the current mainstream oncolytic adenovirus with modifications in E1A and the fiber, has been shown to induce impressive objective response and long-term survival ( $>3$ years) in a fraction of patients with recurrent HGG. Responders exhibited initial enlargement of the treated lesions for a few months post treatment, followed by shrinkage and near complete resolution. In accord with preclinical research, post-treatment specimens revealed virus-mediated alteration of the immune tumor microenvironment as evidenced by infiltration of CD8+ T cells and M1-polarized macrophages. These findings are encouraging and together with further information from ongoing studies have a potential to make oncolytic adenovirus a viable option for clinical management of HGG. This review deals with this timely topic; we will describe both preclinical and clinical development of oncolytic adenovirus therapy for $\mathrm{HGG}$, summarize updated knowledge on clinical trials and discuss challenges that the field currently faces.
\end{abstract}

Keywords: oncolytic adenovirus, high-grade, glioma, glioblastoma, immunotherapy, tumor microenvironment, pseudo-progression

\section{Introduction}

Glioma is a group of neoplasms that primarily arise within the central nervous system (CNS). The current 2016 World Health Organization (WHO) classification uses both histology and genetic molecular features to define gliomas into subtypes and malignancy grade: grades I-IV. ${ }^{1}$ Grades III and IV are considered high-grade (i.e., malignant) gliomas (HGG). Glioblastoma (GBM), grade IV, is the most common glioma typically affecting adults, and includes GBM, IDH-wildtype and GBM, IDH-mutant that each show distinct clinical characteristics. GBM, in general, is characterized by aggressive and infiltrative growth and resistance to therapy. The prognosis of IDH-wildtype GBM is very poor with the median survival of 15 months despite the current standard treatment consisting of a combination of surgical resection, radiation and chemotherapy. ${ }^{2}$ HGG also affect children, and include diffuse mid-line glioma, histone3 K27M mutant and HGG in the
Correspondence: Hiroaki Wakimoto Department of Neurosurgery,

Massachusetts General Hospital, Harvard Medical School, Boston, MA, USA

Tel + 1617-643-5987

Fax +1617-643-3422

Email hwakimoto@mgh.harvard.edu 
cerebral hemispheres. Recent large-scale genetic studies have vastly advanced our understanding of molecular background of both adult and pediatric HGG, and led to clinical testing of numerous molecular-targeted strategies. However, no molecular targeting agents have been shown to extend the overall survival of patients with HGG. The development of novel therapies for HGG is highly needed.

The concept of applying virus to the treatment of cancer is old and was clinically tested in the 1950-1970s. ${ }^{3,4}$ It was in the early 1990s when technology to engineer viral genome first enabled the generation of oncolytic virus (OV) as a cancer-selective therapeutic. ${ }^{5}$ A variety of genetically modified viruses and some naturally occurring viruses have been developed as OV that possesses the ability to replicate in cancer cells and kill them but spare normal cells. The basic OV effect is a direct killing of host cancer cells following its selective replication in tumor cells. Upon cancer cell killing, many OVs induce inflammatory and anti-tumor immune responses that have been increasingly shown to play a major role in overall anti-cancer effects mediated by OV. In addition, genetic modification of OV allows loading of a new function such as therapeutic gene expression or selective infectability to increase efficacy and safety. ${ }^{6}$ A number of virus species, both DNA and RNA viruses, have been studied as OV platforms for cancer therapy, such as herpes simplex virus (HSV), adenovirus, vaccinia virus, reovirus, poliovirus and measles virus. In 2015, FDA approved talimogene laherparepvec (T-VEC), a genetically modified HSV, for advanced melanoma as the first OV therapeutic in the US. ${ }^{7}$

Extensive preclinical and clinical research conducted in the past three decades has accumulated a body of evidence that supports that HGG, in particular GBM, is an appropriate target of OV therapy. Along with oncolytic HSV, oncolytic adenovirus is one of the most studied and promising OVs in the treatment of HGG, with multiple oncolytic adenovirus clinical trials currently ongoing in patients with $\mathrm{HGG}^{8}{ }^{8}$ In this review article, we will summarize preclinical and clinical development of oncolytic adenovirus therapies for HGG and discuss challenges and future directions to advance the field.

\section{History Of The Development Of Conditionally Replicative Adenoviruses (CRAd)}

Adenoviruses are non-enveloped viruses with an icosahedral capsid that contains a double-stranded DNA genome of about $36 \mathrm{~kb}$ in size. They have a broad range of vertebrate hosts, from fish to humans, showing species-specificity. In human adenovirus, 57 serotypes have been identified. ${ }^{9}$ Depending on the serotype, human adenoviruses cause various disease conditions such as respiratory disease, conjunctivitis, gastroenteritis and myocarditis. The well-understood adenovirus biology allows opportunities for genetic manipulation and tailored gene modifications to generate oncolytic adenoviruses, i.e. conditionally replicative adenovirus (CRAd). With regard to manufacturing, CRAd can be produced at high titer and particles are of excellent physicochemical stability. ${ }^{10,11}$

\section{Ist Generation Of CRAd: EIB-55kD Deleted Onyx-0I5}

d11520 (Onyx-015) is the first genome-modified CRAd that is based on human adenovirus type $2 / 5$ chimera. ${ }^{12}$ Onyx-015 has a large deletion at the E1B locus, and does not express E1B-55kD. When wild-type adenovirus infects cells and forces entry into the $\mathrm{S}$ phase triggering p53-mediated apoptosis, the E1B-55kD protein binds and inactivates p53, abrogating p53-mediated apoptosis and enabling the virus to replicate. Onyx-015 is unable to replicate in normal cells due to the deletion of this E1B$55 \mathrm{kD}$, and was initially shown to replicate only in tumor cells lacking p53. However, subsequent studies revealed that Onyx-015 was not selective to p53-defective cells as it replicated in cancer cells having wild-type p53. ${ }^{13-15} \mathrm{On}$ the other hand, tumor cells exist that do not support replication of Onyx-015. Multi-functional E1B-55kD mediates export of late adenoviral mRNA and tumor cells resistant to Onyx-015 do not provide the RNA export functions of E1B-55kD. ${ }^{16}$ Heat shock at $39.4^{\circ} \mathrm{C}$ rescued the mRNA export function of E1B-55kD and enabled efficient replication of E1B-55kD-deletion mutants. ${ }^{17}$

Onyx-015 clinical trials have been conducted in several types of cancer, and a Phase I trial for malignant glioma was reported in $2004 .{ }^{18}$ In this trial, Onyx-015 was injected into the brain that surrounded a surgically resected glioma. None of a total of 24 patients experienced serious adverse events related to Onyx-015. Although lymphocytic and plasma cell infiltrates were found within tumors histologically, no definite anti-tumor efficacy was demonstrated in this trial. After an unsuccessful Phase III trial of combination therapy of chemotherapy and Onyx- 015 in head and neck cancer patients (NCT00006106), ${ }^{19,20}$ clinical development of Onyx-015 discontinued in the United States. In China, combination therapy of intratumoral injection of H101, a CRAd very similar to Onyx-015, 
and chemotherapy demonstrated promising efficacy for head and neck cancer. ${ }^{21}$ In 2005, H101 (Oncorine) was approved as the world's first OV in China. ${ }^{22}$ Currently, H101 trials for hepatocellular carcinoma are underway in China (NCT03790059, NCT03780049).

\section{2nd Generation CRAd: Delta-24-RGD (DNX-240I)}

The presence of multiple adenoviral genes that target cellular cell cycle regulators provided the opportunity to develop oncolytic adenoviruses targeting new pathways. Since many cancers including gliomas have deficiencies in the $\mathrm{Rb}$ (retinoblastoma) tumor suppressor pathway, virus therapy targeting the $\mathrm{Rb}$ pathway was developed as the second generation of CRAd. ${ }^{23}$ E1A-delta24 (Delta-24) was based on human adenovirus type 5 and had a 24-base pair deletion in the $\mathrm{Rb}$-binding domain of the E1A gene. The major function of E1A protein is to bind to $\mathrm{Rb}$ protein and release transcription factor E2F from the Rb-E2F complex, promoting E2Fdriven transcription of genes associated with the $\mathrm{S}$ phase (e.g. DNA metabolism) and thereby viral replication. ${ }^{24}$ Delta-24 cannot replicate in cells with intact $\mathrm{Rb}$ due to the inability of the mutant $\mathrm{E} 1 \mathrm{~A}$ to bind to $\mathrm{Rb}$ protein. On the other hand, Delta-24 can replicate in tumor cells in which $\mathrm{Rb}$ is deleted, since E2F that exists in a free state promotes gene transcription and transition to the $\mathrm{S}$ phase. At about the same time, d1922-947, another oncolytic adenovirus containing a 24 base pair deletion within the Rb-binding region of E1A, was developed and showed better in vivo efficacy than dl1520 (Onyx-015). ${ }^{25}$

Human adenovirus type 5 binds to Coxsackievirus and adenovirus receptor (CAR) on the cell surface and enters the host cells. Although CAR is expressed in a variety of normal cells, ${ }^{26}$ several cancers including glioma express lower levels of CAR, ${ }^{27,28}$ causing poor infectivity of CRAd in cancer cell lines. In order to overcome this problem, Suzuki et al developed the approach that incorporates a sequence encoding an RGD (Arg-Gly-Asp) peptide in a cyclic conformation (RGD4C) into the HI loop of the fiber knob. ${ }^{29}$ The RGD sequence interacts with $\alpha \mathrm{v}$ integrins on the cell surface ${ }^{30}$ that many cancer cells express, including HGG known to highly express integrin $\alpha \mathrm{v} \beta 3 .{ }^{31}$ The fiber modification with RGD improved the infection rate of CRAd in cancer cell lines and enabled CAR independent infection. The resulting CRAd, Delta-24-RGD (DNX-2401) having a 24-bp deletion in the E1A gene and an RGD motif in fiber protein, became the prototype of a newer generation of oncolytic adenoviruses.
Since the late 2000s, a number of clinical trials started testing DNX-2401 for HGG (Table 1), and the first report of a Phase I trial was published in $2018,{ }^{32}$ as detailed below.

\section{3rd Generation CRAds}

Continued efforts have been made to create CRAd that are more efficacious and cancer-selective. Many novel CRAds have been developed based on DNX-2401 and tested for their effects on HGGs in translational research. To express mutant E1A in a cancer-selective manner, Alonso et al generated the oncolytic adenovirus ICOVIR5 which contains an insulated E2F1-responsive promoter and a Kozak sequence preceding the E1A start codon. ${ }^{33}$ DeltaE1A expression driven by a promoter consisting of four palindromic E2F-binding sites and one Sp-1 binding site in ICOVIR15 increased cytotoxicity and antitumor activity. ${ }^{34}$ ICOVIR17 is a modified version of ICOVIR15 and is armed with cDNA for human hyaluronidase $\mathrm{PH} 20 .{ }^{35}$ Hyaluronidase-mediated degradation of hyaluronic acid in the tumor extracellular matrix enabled ICOVIR17 to spread better within orthotopic HGG xenografts and extended animal survival. ${ }^{35,36}$ Furthermore, VCN-01, in which RGD was inserted in the fiber shaft instead of fiber knob to improve the infectivity of ICOVIR17, similarly produced a significant survival prolonging effect in an HGG xenograft model. ${ }^{37,38}$ Although these viruses have not entered clinical trials for HGG, Phase I trials of VCN-01 are active for retinoblastoma (EudraCT 2016-001060-11) and pancreatic adenocarcinoma (NCT02045589 and NCT02045602) in Spain.

Delta-24-RGDOX was generated by arming DNX2401 with mouse OX40L (OX40 ligand) cDNA to activate $\mathrm{T}$ cells through the activating receptor OX40 on the surface of $\mathrm{T}$ cells. ${ }^{39}$ Intratumoral injection of Delta-24RGDOX recruited more CD4+ and CD8 $+\mathrm{T}$ cells in tumor sites than Delta-24-RGD, and significantly prolonged survival time in an immuno-competent mouse GBM model. Combination therapy with anti-PD-L1 antibody further increased the therapeutic effect on survival. A Phase I trial of DNX-2440, which is armed with human OX40L, is currently ongoing for patients with recurrent glioblastoma (NCT03714334).

The genomic structures of 2nd and 3rd generations of CRAd are illustrated in Figure 1.

\section{Induction Of Anti-Tumor Immune Response By CRAd}

The CNS has long been considered the "immunologically privileged site" representing an immunologically distinct 
Table I Current Clinical Trials Studying Oncolytic Adenovirus In High-Grade Glioma

\begin{tabular}{|c|c|c|c|c|c|c|c|c|}
\hline Trial Number & Phase & Virus & $\begin{array}{l}\text { Other } \\
\text { Treatments }\end{array}$ & Target & Status & $\begin{array}{l}\text { Start } \\
\text { Date }\end{array}$ & Country & Report \\
\hline NCT03896568 & I & DNX-240I & Surgery & $\begin{array}{l}\text { Recurrent high-grade } \\
\text { glioma }\end{array}$ & Recruiting & Feb. 2019 & USA & \\
\hline $\begin{array}{l}\text { NCT03 I } 78032 \\
2016-001577-33 \\
\text { (D24-DIPG) }\end{array}$ & I & DNX-240I & & Naïve DIPG & Recruiting & May. 2017 & Spain & $\begin{array}{l}\text { Martinez- } \\
\text { Velez } \\
2019\end{array}$ \\
\hline $\begin{array}{l}\text { NCT02798406 } \\
\text { (CAPTIVE) }\end{array}$ & II & DNX-240I & Pembrolizumab & $\begin{array}{l}\text { Recurrent } \\
\text { glioblastoma }\end{array}$ & $\begin{array}{l}\text { Active, not } \\
\text { recruiting }\end{array}$ & Jun. 2016 & USA & $\begin{array}{l}\text { Zadeh } \\
2018\end{array}$ \\
\hline $\begin{array}{l}\text { NCT02197I69 } \\
\text { (TARGET-I) }\end{array}$ & I & DNX-240I & $\mathrm{IFN} \gamma$ & $\begin{array}{l}\text { Recurrent } \\
\text { glioblastoma and } \\
\text { gliosarcoma }\end{array}$ & Completed & Sep. 2014 & USA & $\begin{array}{l}\text { Tufaro } \\
2016\end{array}$ \\
\hline $\begin{array}{l}\text { NCT0I956734 } \\
\text { (D24GBM) }\end{array}$ & 1 & DNX-240I & TMZ & $\begin{array}{l}\text { Recurrent } \\
\text { glioblastoma }\end{array}$ & Completed & Sep. 2013 & Spain & \\
\hline NCT0I5825I6 & I, II & $\begin{array}{l}\text { d24-RGD } \\
(D N X-240 I)\end{array}$ & & $\begin{array}{l}\text { Recurrent } \\
\text { glioblastoma }\end{array}$ & Completed & Jun. 2010 & Netherlands & \\
\hline NCT00805376 & I & DNX-240I & & $\begin{array}{l}\text { Recurrent malignant } \\
\text { glioma }\end{array}$ & Completed & Feb. 2009 & USA & Lang 2018 \\
\hline 2007-00 I I04-2 I & I, II & DNX-240I & & $\begin{array}{l}\text { Recurrent } \\
\text { glioblastoma }\end{array}$ & Ongoing & Jan. 2009 & Netherlands & \\
\hline $\begin{array}{l}2016-001600-40 \\
(\mathrm{D} 2401 \mathrm{GBM} 2)\end{array}$ & II & DNX-240I & Standard care & $\begin{array}{l}\text { Newly diagnosed } \\
\text { glioblastoma }\end{array}$ & Ongoing & Sep. 2016 & Spain & \\
\hline NCT037I4334 & 1 & DNX-2440 & & $\begin{array}{l}\text { Recurrent } \\
\text { glioblastoma }\end{array}$ & Recruiting & Nov. 2018 & Spain & \\
\hline NCT03072I 34 & I & $\begin{array}{l}\text { NSC-CRAd- } \\
\text { Survivin-pk7 }\end{array}$ & & $\begin{array}{l}\text { Newly diagnosed } \\
\text { malignant glioma }\end{array}$ & Recruiting & Apr. 2017 & USA & \\
\hline
\end{tabular}

environment from other organs. Glioma in the brain induces angiogenesis and disruption of the blood brain barrier (BBB), which allows various drugs and immune cells to enter the tumor. However, the microenvironment of GBM is highly immunosuppressive characterized by secretion of immunosuppressive cytokines (TGF- $\beta$, IL10 , etc.), and the dominance of immuno-suppressive immune cells such as regulatory $\mathrm{T}$ cells, functionally exhausted $\mathrm{T}$ cells, myeloid-derived suppressor cells and M2-polarized tumor-associated macrophages. ${ }^{40-43}$ In recent years, immune checkpoint blockade has emerged as a novel immune-therapeutic modality for cancer, but unfortunately, the Phase III CheckMate-143 study (NCT02017717) investigating the anti-PD-1 nivolumab monotherapy in recurrent GBM patients did not extend overall survival compared with bevacizumab (Reardon et al, WFNOS2017 ${ }^{44}$ ). This result may be attributable to the immunosuppressive microenvironment of GBM and suggest that combination with other therapy that stimulates immune responses may enhance the efficacy of immune checkpoint inhibitors in GBM patients. ${ }^{45}$

CRAd has been shown to alter the immune microenvironment in experimental GBM in mice. ${ }^{46-48}$ Delta-24RGD (DNX-2401) treatment of GL261 murine GBM recruited $\mathrm{F} 4 / 80+$ macrophages, NK cells and CD4+ and CD8 $+\mathrm{T}$ cells to the tumor site in C57/BL6 mice, and induced $\mathrm{T}$ cells to react to the virus and tumor cells. ${ }^{46,47}$ These immune effects mediated the therapeutic efficacy of DNX-2401 as co-treatment with dexamethasone, an immunosuppressive steroid, abrogated the survival benefit in mice. ${ }^{47}$ Thus, adenoviral modification of the immunological landscape within HGG can set a stage for enhancing the efficacy of immunotherapy for HGG. Indeed, Jiang et al showed that the combination therapy with 


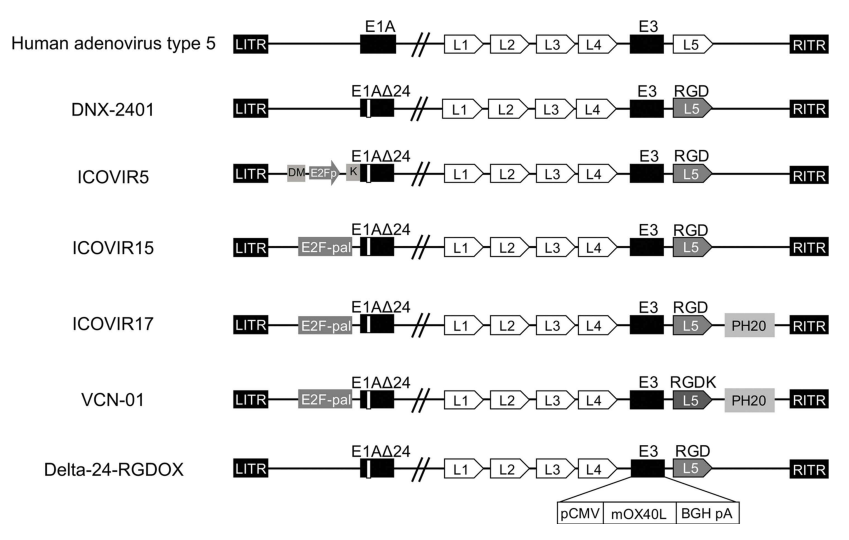

Figure I Genomic structure of oncolytic adenoviruses currently used in preclinical and clinical studies on high-grade glioma. ITR, inverted terminal repeat. EIAD24: a deletion of 24 base pairs within the EIA region. DM: insulator DM-I. E2Fp: E2F-responsive promoter. K: a Kozak sequence. E2F-pal: E2F-responsive palindromes (8 E2F-binding sites). $\mathrm{PH} 20$ : human sperm $\mathrm{PH} 20$ hyaluronidase cDNA. RGD: an RGD integrin-binding motif in the HI loop of the fiber. RGDK: RGDK in the putative heparin sulfate-glycosaminoglycans binding domain KKTK in the fiber shaft. PCMV: the cytomegalovirus promoter. mOX40L: mouse OX40L cDNA. BGH pA: bovine growth hormone poly-adenylation signal. The mOX40L expression cassette replaces the E3 region in Delta-24-RGDOX.

Delta-24-RGDOX and anti-PD-L1 antibody, both administered intratumorally twice, effectively prolonged the survival of murine GL261 GBM model, ${ }^{39}$ providing a rationale for clinical testing of this immunotherapeutic strategy.

\section{Clinical Trial Of DNX-240 I For Malignant Gliomas}

Table 1 summarizes clinical trials of CRAd for HGGs that recently completed or are currently active.

\section{Treatment With DNX-240I In Recurrent High-Grade Gliomas}

Lang et al reported the results of a Phase I trial of DNX2401 for recurrent malignant glioma ${ }^{32}$ (NCT00805376). Thirty-seven patients were enrolled and divided into Group A $(\mathrm{n}=25)$ and Group B $(\mathrm{n}=12)$. In Group A, DNX-2401 at escalating doses $\left(1 \times 10^{7}\right.$ to $3 \times 10^{10}$ viral particles) was stereotactically injected into the tumor after biopsy confirming tumor recurrence. Following treatment, $20 \%$ of patients ( 5 of 25 ) survived more than 3 years, and dramatic tumor reduction $(95 \%$ or more, CR) was seen in 3 patients, whose progression-free survival (PFS) was over 3 years. To investigate the mechanism of virus treatment, tumors in Group B were injected with DNX-2401 (1 x 10 to $3 \times 10^{8}$ viral particles) through catheters inserted into the tumors and the tumors were resected 14 days later, along with a second DNX-2401 injection to the wall of the resection cavity. Interestingly, MRI of the 3 complete responders showed an initial increase in contrast enhancement within 4 months after injection of DNX-2401, suggesting an immune or inflammatory response, followed by regression over 1-1.5 years. Immunohistochemical analysis showed evidence of DNX-2401 replication within the tumor in 6 of 11 Group B tumors (55\%) 2 weeks postvirus treatment. Furthermore, intratumoral infiltration of CD4+ T cells and T-bet + cells, suggestive of a helper 1 (Th1) response, was observed. Among immune checkpoint proteins, expression of TIM3, but not PD-L1, was decreased after treatment with DNX-2401. Histological examination of a lesion that developed distant from the treated tumor and was resected in one of the complete responders revealed inflammatory cells, with no evidence of tumor cells, suggesting a response driven by adaptive immune memory. Thus, this clinical study for the first time showed direct oncolytic effects in human brain tumors and provided evidence for elicitation of anti-glioma immune responses. No dose-limiting toxicities were observed in this trial. Adverse effects were reported in $15 \%$ of patients, but no serious events of grade 3 or higher were noted that were considered to be related to the virus, supporting the safety.

In the Netherlands, a Phase I/II clinical trial was initiated in 2010 testing DNX-2401 for recurrent glioblastoma (NCT01582516). The virus is administered using convection-enhanced delivery via catheters targeting tumor mass as well as the surrounding infiltrated brain. Using tumor tissues and cerebrospinal fluid (CSF) collected from the study participants, van den Bossche et al studied the impact of DNX-2401 injection on tumor macrophages. ${ }^{49}$ In some patients, DNX-2401 treatment increased the CSF concentrations of cytokines such as TNF, IL6 and IFN $\gamma$, and such CSF was able to increase the levels of CD64, a marker of M1-polarization, on macrophages in vitro. A tumor that re-recurred and was resected 26 months after DNX-2401 therapy provided a valuable research material that suggested a prolonged shift of a macrophage phenotype from M2 to M1. The feasibility and efficacy results of the trial have not been published.

\section{DNX-240I And Immunotherapy}

Because of the ability of CRAd to alter the immune status by turning the cold tumor microenvironment to hot (inflamed), combining CRAd with immune-modulating therapies is a rational approach, which is supported by preclinical studies for $\mathrm{GBM}^{39}$ and other cancers. ${ }^{50-52}$ 
Currently, a Phase II multicenter study is investigating a combination therapy of DNX-2401 and Pembrolizumab (anti-PD-1 antibody) for recurrent malignant glioma (CAPTIVE, NCT02798406). In this trial, a single intratumoral dose of DNX-2401 $\left(5 \times 10^{8}, 5 \times 10^{9}\right.$ and $5 \times 10^{10}$ virus particles) is injected via cannula inserted into the tumor, and followed 7 days later by intravenous injection of 200 mg pembrolizumab every 3 weeks for up to 24 months or until confirmed progression, intolerable toxicity or study withdrawal. Interim outcome was reported at the SNO 2018 annual meeting that 23 patients have been treated and DNX-2401 followed by pembrolizumab has been well tolerated (Zadeh et al, ${ }^{53} \mathrm{SNO} 2018$ ). Preliminary efficacy is encouraging as two partial responses and $100 \%$ 9-month survival for the first 7 patients treated were noted. Publication of longer follow-up data is eagerly awaited.

\section{Addition Of IFN $\gamma$ To DNX-240 I Did Not Improve Survival}

Lang et al reported at ASCO 2017 the Phase Ib trial of DNX2401 with or without interferon gamma (IFN $\gamma$ ) for recurrent glioblastoma (TARGET-I ${ }^{54}$ ). Twenty-seven patients were enrolled and randomized to intratumoral DNX-2401 followed by subcutaneous IFN $\gamma(\mathrm{n}=18)$ or to DNX-2401 alone $(n=9)$. Due to the poor tolerability of IFN $\gamma$, the median duration of treatment was only 6 weeks. Overall survival of 12 months and 18 months for all patients enrolled was 33\% and $22 \%$, respectively, regardless of treatment assignment. Three patients (DNX-2401, n=1; DNX-2401 with IFN $\gamma$, $\mathrm{n}=2$ ) remain alive over 1.5 years after the treatments.

\section{DNX-240I Combination With TMZ}

The alkylating agent Temozolomide (TMZ) is part of the standard treatment for newly diagnosed GBM. ${ }^{2}$ TMZ chemosensitivity is known to depend on epigenetic silencing of $\mathrm{O}^{6}$-methylguanine-DNA methyltransferase (MGMT) by promoter methylation. ${ }^{55}$ Pre-clinically, DNX-2401 infection was shown to reduce MGMT levels in human GBM cell lines (U87 and T98G) in vitro and decrease IC50 of TMZ. ${ }^{56}$ In vivo, combination therapy of DNX-2401 and TMZ significantly extended survival in a GBM xenograft model in immunodeficient mouse. ${ }^{56}$ Kleijn et al subsequently showed that combination was also efficacious in immunocompetent mouse GBM models. ${ }^{57}$ These studies provided a rationale for the Phase I trial of the combination therapy of DNX-2401 and TMZ that is ongoing in Spain for recurrent glioblastoma (NCT01956734).

\section{DNX-2440 - Oncolytic Adenovirus}

\section{Armed With T Cell Stimulator}

A Phase I trial of intratumoral injection of DNX-2440, a modified version of DNX-2401 armed with OX40L, for recurrent glioblastoma is ongoing in Spain (NCT03714334). This is the first clinical trial testing a 3rd generation CRAd for malignant glioma.

\section{DNX-240I In Pediatric Glioma}

Pediatric high-grade gliomas (pHGG) are distinct from adult HGG as pHGG harbor genetic drivers that adult HGGs do not and arise at different CNS locations. Diffuse intrinsic pontine glioma (DIPG) is an aggressive pHGG that arises in the brainstem and is characterized by histone H3 K27M mutation that is also frequent in pediatric gliomas in the midline structures such as the thalamus. pHGG of the cerebral cortex typically harbors pG34R/V histone $\mathrm{H} 3$ mutations. In contrast, $\mathrm{H} 3$ mutations are extremely rare in adult HGGs. ${ }^{58,59}$ Because of the vital functions of the brainstem, resection is not a therapeutic option for DIPG. Radiotherapy is the standard of care for DIPG, but this only improves the quality of life for several months and is not curative. ${ }^{60}$

Preclinically, Martinez-Velez et al reported that DNX2401 viral infection and replication were observed in several human and murine DIPG cell lines. Intratumoral administration of DNX-2401 was safe in mice and resulted in a significant increase of survival rate in both immunodeficient and immunocompetent models of pHGG and DIPG. ${ }^{61}$ The same group further showed that DNX-2401 treatment downregulated DNA damage repair proteins and when combined with radiotherapy mediated a synergistic anti-glioma effect in mouse models of pHGG and DIPG. ${ }^{62}$ Currently, a Phase I trial of DNX-2401 for newly diagnosed DIPG is ongoing in Spain (NCT03178032 ${ }^{63}$ ). And a case report in this trial showed the tolerability of DNX2401 in an 8-year-old DIPG patient. DNX-2401 was injected via a catheter into the tumor within the pons following biopsy and the procedure was not associated with safety problems or new neurological deficit. ${ }^{64}$ After 3-4 weeks of virus administration, patients will start receiving standard radiation therapy.

\section{Stem Cell Delivery Of CRAd To HGG}

Because of their ability to migrate preferentially toward tumor cells, stem cells have been explored as vehicles to deliver antitumor agents including OV to brain tumors. ${ }^{65-67}$ 
Preclinically, combination of different types of stem cells and CRAd have been studied as experimental treatments of glioma; mesenchymal stem cell MSC-Delta24-RGD, ${ }^{68}$ and MSC-ICOVIR17, ${ }^{36}$ MSC-CRAd-CXCR4-5/3, ${ }^{69}$ neural stem cells (NSC)-CRAd-survivin-pk $7^{69-72}$ demonstrated antiglioma activity. CRAd-CXCR4-5/3 and CRAd survivinpk7 are transcriptionally targeted CRAd using tumor-specific $\mathrm{C}-\mathrm{X}-\mathrm{C}$ chemokine receptor 4 (CXCR4) and survivin promotor, respectively, to control E1A expression and target the viruses to GBM. ${ }^{73,74}$ CRAd-CXCR4-5/3 has a chimeric Ad $5 / 3$ fiber (chimera of the shaft of human adenovirus type 5 and the knob of human adenovirus type 3 ) that targets CD46 or CD80/86 cellular receptors and exhibits increased transduction of malignant glioma compared with wild-type Ad5. ${ }^{73,75}$ CRAd-Survivin-pk7 has fiber modification with pk7 encoding polylysine that was designed to increase transduction of malignant glioma by direct binding to heparan sulfate and polyanionic cellular receptors ${ }^{74,76,77}$ Currently, a Phase I trial is ongoing in the US (NCT03072134) in which NSC loaded with CRAd-survivin-pk7 are injected into the resection cavity of newly diagnosed GBM.

\section{Gene-Mediated Cytotoxic} Immunotherapy Using Adenoviral Vectors Adenovirus vectors that deliver the thymidine kinase gene of HSV (HSV-tk) have been long studied as a therapeutic strategy for GBM. Adenoviral transduction of HSV-tk in tumor cells followed by systemic administration of a nucleoside analog prodrug such as ganciclovir induces the phosphorylation of the prodrug, termination of DNA replication and death in dividing cells, as well as neighboring cells through the bystander effect. ${ }^{78,79}$ The death in cancer cells results in release of tumor neoantigens and elicitation of anti-tumor cellular immune responses. ${ }^{78,80}$ Although this modality, so-called gene-mediated cytotoxic immunotherapy (GMCI), is outside the field of OV therapy due to use of replication-defective vectors, induction of tumor-selective immunogenic cell death may underlie a mechanism-ofaction common in GMCI and CRAd therapies.

In neuro-oncology, Ad-HSV-tk (AdV-tk) was first tested clinically in a Phase I study in patients with recurrent malignant glioma. ${ }^{81}$ A subsequent Phase Ib dose-escalation study for newly diagnosed $\mathrm{GBM}^{82}$ confirmed the tolerability and safety of the local injection of the vector and oral valacyclovir administration. A Phase II study conducted in parallel showed an increase in overall survival of patients receiving GMCI, as compared with those treated with the standard of care, with prominent efficacy observed when gross total resection was followed by GMCI. Recently, a potential efficacy of GMCI was reported in pediatric patients with glioma (NCT00634231). ${ }^{83}$ Currently, a Phase I trial is investigating the combination of GMCI and immune checkpoint blockade with novolumab for newly diagnosed high-grade gliomas (NCT03576612). Another interesting clinical trial for newly diagnosed malignant gliomas involves a rational combination of two adenoviral vectors that express HSV-tk or Flt3L, a cytokine that differentiates precursors into dendritic cells and recruits those to the brain tumor environment (NCT01811992). ${ }^{84}$

\section{Discussion - Challenges And Future Directions}

During the last 10 years, research on CRAd has been rapidly evolving as a potential novel treatment for patients with HGG. Extensive efforts to translate findings gained from preclinical research using animal models have resulted in a number of early-stage (Phase I and II) clinical trials that have completed or are active in the US and Europe (Table 1). The results of these clinical investigations, regarding feasibility, safety and efficacy, have largely been unpublished yet. As shown by the report by Lang et al, ${ }^{32}$ survival and radiographic (MRI) follow-up as well as analysis of biospecimens including tumors, CSF, serum, sputum and urine all provide valuable information that helps us understand the complex biological processes and mechanisms-of-action of oncolytic adenovirus therapy (Figure 2). Detailed reports of trials are therefore awaited by the large research community and patients alike. DNX2401 is currently the mainstream CRAd that is under vigorous testing in multiple trials, and may become the first FDA-approved CRAd. That $20 \%$ of patients with recurrent HGGs (mostly IDH wildtype GBM) survived over 3 years is encouraging and such a long survival tail in a fraction of patients is consistent with the results with PVS-RIPO (poliovirus). ${ }^{85}$

Since the clinical benefits of DNX-2401 were very variable between patients, ${ }^{32}$ search of biomarkers of response is one of the critical tasks. One of the intriguing findings that Lang et al reported with the DNX-2401 trial was that, in all three patients who responded extremely well to DNX-2401 treatment, contrast enhancement of treated lesions showed an increase on MRI between 1 and 6 months after therapy, which then subsided and almost disappeared (Figure 2). This initial enlargement of 


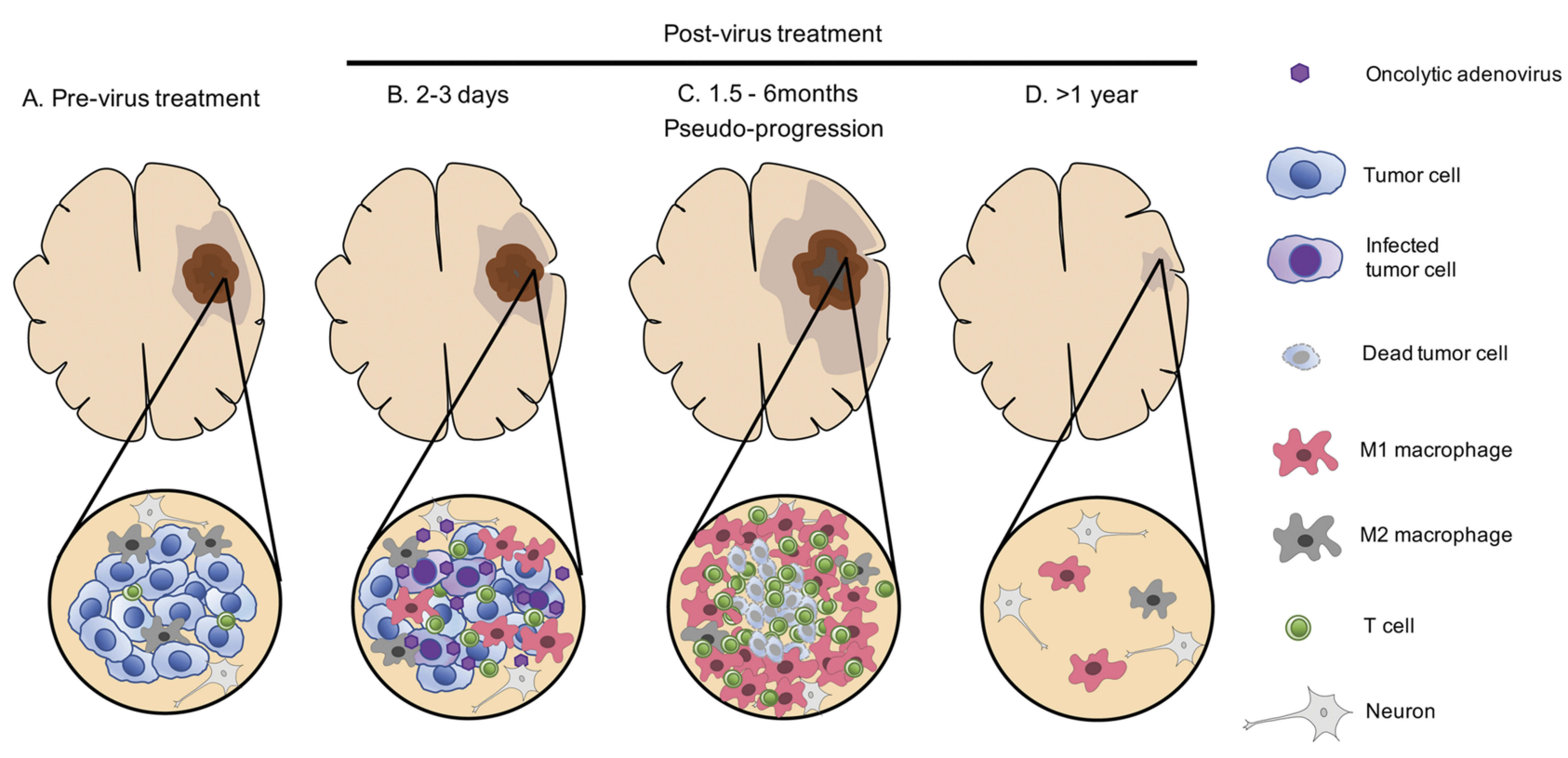

Figure 2 Dynamic changes that occur over time within the tumor microenvironment after oncolytic adenovirus therapy of glioblastoma. Upper, macroscopic and radiographic changes. Lower, microscopic-level changes. (A) Before treatment, the GBM tumor microenvironment is immune-suppressive as characterized by M2-polarized macrophages and few effector $T$ cells. (B) A few days after virus administration, oncolytic adenovirus is actively replicating within the tumor, starting to induce the recruitment of effector $\mathrm{T}$ cells and macrophages with a shift from an $\mathrm{M} 2$ to $\mathrm{Ml}$ phenotype. (C) A few months later, the tumor exhibits an increase in size on magnetic resonance imaging (MRI). At this stage, virus has been cleared, but an active inflammatory reaction persists with the infiltration of immune cells such as $\mathrm{T}$ cells and $\mathrm{MI}$ polarized macrophages. Tumor cells are essentially absent (necrosis), despite the worsening of imaging (pseudo-progression). (D) During the follow-up, inflammation gradually subsides and MRI shows progressive regression of the lesion and associated edema, which could take over a year.

the lesions in responders is considered pseudo-progression (therapy-mediated tumor enhancement), a phenomenon frequently reported in OV therapy for other cancers ${ }^{3}$ and explained as inflammatory responses triggered by the virus. The identification of pseudo-progression after clinical CRAd therapy for HGGs raises several questions. First, how can pseudo-progression and recurrence/progression be distinguished, and for this purpose if biospecimens useful or imaging modalities sufficient? Second, is pseudoprogression a reliable biomarker of response and clinical benefit? The Lang report seems to be supportive, but did not provide definitive yes to this question. Third, when pseudo-progression directly causes local brain symptoms or elevation of intracranial pressure, will the use of glucocorticosteroid be appropriate to noninvasively manage the conditions without negatively impacting anti-tumor immune responses and ultimate outcomes? Accumulation of clinical data may be able to address these questions.

The DNX-2401 trial validated prior preclinical research that injection of CRAd elicits the recruitment of immune cells, particularly T cells, to the tumor site. This is an indication that immunocompetent mouse model of $\mathrm{HGG}^{39,46,47,49,57,61,86}$ was useful to predict, at least, some biological changes evoked in patients by CRAd therapy. However, all current CRAds are based on human adenovirus that replicates poorly in mouse cells. ${ }^{87}$ To overcome this problem, multiple administration of highdose CRAd has been the commonly used approach to mimic the situation of good virus replication. ${ }^{39,51}$ Alternative animal models such as Syrian hamster, ${ }^{88}$ pig $^{89}$ or use of humanized mouse models ${ }^{50,90}$ are being developed and could be shown in the future to better represent clinical scenarios of CRAd therapy.

The field of CRAd is rapidly evolving. The 3rd generation of CRAd, designed to be more potent and maintain safety, are entering several cancer clinical trials as monotherapy or combination, ${ }^{67}$ including a DNX-2440 trial for GBM (NCT03714334). We expect that knowledge on efficacy, feasibility, safety and mechanisms-of-action that will be gained from the current CRAd trails in neuro-oncology will boost efforts of developing newer generations of CRAd and help accelerate transition to their clinical evaluation.

\section{Disclosure}

The authors report no conflicts of interest in this work.

\section{References}

1. Louis D, von Deimling A, Cavenee W 1. Disffuse astrocytic and oligodendroglial tumors. WHO classifivation of tumours of the central nervous system Revised 4th IARC; 2016; Lyon, France:15-78. 
2. Stupp R, Mason WP, van Den Bent MJ, et al. Radiotherapy plus concomitant and adjuvant temozolomide for glioblastoma. $N$ Engl $J$ Med. 2005;352(10):987-996. doi:10.1056/NEJMoa043330

3. Larson C, Oronsky B, Scicinski J, et al. Going viral: a review of replication-selective oncolytic adenoviruses. Oncotarget. 2015;6 (24):19976-19989. doi:10.18632/oncotarget.5116

4. Kelly E, Russell SJ. History of oncolytic viruses: genesis to genetic engineering. Mol Ther. 2007;15(4):651-659. doi:10.1038/sj.mt.6300108

5. Alemany R. Viruses in cancer treatment. Clin Transl Oncol. 2013;15 (3):182-188. doi:10.1007/s12094-012-0951-7

6. Bell J, McFadden G. Viruses for tumor therapy. Cell Host Microbe. 2014;15(3):260-265. doi:10.1016/j.chom.2014.01.002

7. Andtbacka RH, Kaufman HL, Collichio F, et al. Talimogene laherparepvec improves durable response rate in patients with advanced melanoma. J Clin Oncol. 2015;33(25):2780-2788. doi:10.1200/ JCO.2014.58.3377

8. Cervera-Carrascon V, Havunen R, Hemminki A. Oncolytic adenoviruses: a game changer approach in the battle between cancer and the immune system. Expert Opin Biol Ther. 2019;19(5):443-455. doi:10.1080/14712598.2019.1595582

9. Alemany R. Oncolytic adenoviruses in cancer treatment. Biomedicines. 2014;2(1):36-49. doi:10.3390/biomedicines2010036

10. Niemann J, Kuhnel F. Oncolytic viruses: adenoviruses. Virus Genes. 2017;53(5):700-706. doi:10.1007/s11262-017-1488-1

11. Baker AT, Aguirre-Hernandez C, Hallden G, Parker AL. Designer oncolytic adenovirus: coming of age. Cancers (Basel). 2018;10(6). doi:10.3390/cancers 10110400

12. Bischoff JR, Kirn DH, Williams A, et al. An adenovirus mutant that replicates selectively in p53-deficient human tumor cells. Science. 1996;274(5286):373-376. doi:10.1126/science.274.5286.373

13. Edwards SJ, Dix BR, Myers CJ, et al. Evidence that replication of the antitumor adenovirus ONYX-015 is not controlled by the p53 and p14(ARF) tumor suppressor genes. J Virol. 2002;76(24):1248312490. doi:10.1128/jvi.76.24.12483-12490.2002

14. Rothmann T, Hengstermann A, Whitaker NJ, Scheffner M, Zur Hausen H. Replication of ONYX-015, a potential anticancer adenovirus, is independent of p53 status in tumor cells. J Virol. 1998;72 (12): $9470-9478$.

15. Geoerger B, Grill J, Opolon P, et al. Oncolytic activity of the E1B-55 kDadeleted adenovirus ONYX-015 is independent of cellular p53 status in human malignant glioma xenografts. Cancer Res. 2002;62(3):764-772.

16. O'Shea CC, Johnson L, Bagus B, et al. Late viral RNA export, rather than p53 inactivation, determines ONYX-015 tumor selectivity. Cancer Cell. 2004;6(6):611-623. doi:10.1016/j.ccr.2004.11.012

17. O'Shea CC, Soria C, Bagus B, McCormick F. Heat shock phenocopies E1B-55K late functions and selectively sensitizes refractory tumor cells to ONYX-015 oncolytic viral therapy. Cancer Cell. 2005;8(1):61-74. doi:10.1016/j.ccr.2005.06.009

18. Chiocca EA, Abbed KM, Tatter S, et al. A phase I open-label, doseescalation, multi-institutional trial of injection with an E1BAttenuated adenovirus, ONYX-015, into the peritumoral region of recurrent malignant gliomas, in the adjuvant setting. Mol Ther. 2004;10(5):958-966. doi:10.1016/j.ymthe.2004.07.021

19. Kirn D. Clinical research results with d11520 (Onyx-015), a replication-selective adenovirus for the treatment of cancer: what have we learned? Gene Ther. 2001;8(2):89-98. doi:10.1038/sj.gt.3301377

20. Wildner O. Clinical trials: the sensitizing side of Onyx-015. Gene Ther. 2005;12(5):386-387.

21. Xia ZJ, Chang JH, Zhang L, et al. Phase III randomized clinical trial of intratumoral injection of E1B gene-deleted adenovirus (H101) combined with cisplatin-based chemotherapy in treating squamous cell cancer of head and neck or esophagus (Article in Chinese). $A i$ Zheng. 2004;23(12):1666-1670.

22. Garber K. China approves world's first oncolytic virus therapy for cancer treatment. $J$ Natl Cancer Inst. 2006;98(5):298-300. doi:10.1093/jnci/djj111
23. Fueyo J, Gomez-Manzano C, Alemany R, et al. A mutant oncolytic adenovirus targeting the $\mathrm{Rb}$ pathway produces anti-glioma effect in vivo. Oncogene. 2000;19(1):2-12. doi:10.1038/sj.onc.12 03251

24. Nevins JR. E2F: a link between the Rb tumor suppressor protein and viral oncoproteins. Science. 1992;258(5081):424-429. doi:10.1126/ science. 1411535

25. Heise C, Hermiston T, Johnson L, et al. An adenovirus E1A mutant that demonstrates potent and selective systemic anti-tumoral efficacy. Nat Med. 2000;6(10):1134-1139. doi:10.1038/80474

26. Reeh M, Bockhorn M, Gorgens D, et al. Presence of the coxsackievirus and adenovirus receptor (CAR) in human neoplasms: a multitumour array analysis. Br J Cancer. 2013;109(7):1848-1858. doi:10.1038/bjc.2013.509

27. Miller CR, Buchsbaum DJ, Reynolds PN, et al. Differential susceptibility of primary and established human glioma cells to adenovirus infection: targeting via the epidermal growth factor receptor achieves fiber receptor-independent gene transfer. Cancer Res. 1998;58 (24):5738-5748.

28. Fuxe J, Liu L, Malin S, Philipson L, Collins VP, Pettersson RF. Expression of the coxsackie and adenovirus receptor in human astrocytic tumors and xenografts. Int $J$ Cancer. 2003;103(6):723-729. doi:10.1002/ijc.10891

29. Suzuki K, Fueyo J, Krasnykh V, Reynolds PN, Curiel DT, Alemany R. A conditionally replicative adenovirus with enhanced infectivity shows improved oncolytic potency. Clin Cancer Res. 2001;7(1):120-126.

30. Pasqualini R, Koivunen E, Ruoslahti E. Alpha v integrins as receptors for tumor targeting by circulating ligands. Nat Biotechnol. 1997;15(6):542-546. doi: 10.1038/nbt0697-542

31. Gladson CL, Cheresh DA. Glioblastoma expression of vitronectin and the alpha v beta 3 integrin. Adhesion mechanism for transformed glial cells. $J$ Clin Invest. 1991;88(6):1924-1932. doi:10.1172/JCI115516

32. Lang FF, Conrad C, Gomez-Manzano C, et al. Phase I study of DNX2401 (Delta-24-RGD) oncolytic adenovirus: replication and immunotherapeutic effects in recurrent malignant glioma. $J$ Clin Oncol. 2018;36(14):1419-1427. doi:10.1200/JCO.2017.75.8219

33. Alonso MM, Cascallo M, Gomez-Manzano C, et al. ICOVIR-5 shows E2F1 addiction and potent antiglioma effect in vivo. Cancer Res. 2007;67(17):8255-8263. doi:10.1158/0008-5472.CAN-06-4675

34. Rojas JJ, Guedan S, Searle PF, et al. Minimal RB-responsive E1A promoter modification to attain potency, selectivity, and transgenearming capacity in oncolytic adenoviruses. Mol Ther. 2010;18 (11):1960-1971. doi:10.1038/mt.2010.173

35. Guedan S, Rojas JJ, Gros A, Mercade E, Cascallo M, Alemany R. Hyaluronidase expression by an oncolytic adenovirus enhances its intratumoral spread and suppresses tumor growth. Mol Ther. 2010;18 (7):1275-1283. doi:10.1038/mt.2010.79

36. Martinez-Quintanilla J, He D, Wakimoto H, Alemany R, Shah K. Encapsulated stem cells loaded with hyaluronidase-expressing oncolytic virus for brain tumor therapy. Mol Ther. 2015;23(1):108-118. doi:10.1038/mt.2014.204

37. Vera B, Martinez-Velez N, Xipell E, et al. Characterization of the antiglioma effect of the oncolytic adenovirus VCN-01. PLoS One. 2016;11(1):e0147211. doi:10.1371/journal.pone.0147211

38. Bayo-Puxan N, Gimenez-Alejandre M, Lavilla-Alonso S, et al. Replacement of adenovirus type 5 fiber shaft heparan sulfate proteoglycan-binding domain with RGD for improved tumor infectivity and targeting. Hum Gene Ther. 2009;20(10):1214-1221. doi:10.1089/ hum. 2009.038

39. Jiang H, Rivera-Molina Y, Gomez-Manzano C, et al. Oncolytic adenovirus and tumor-targeting immune modulatory therapy improve autologous cancer vaccination. Cancer Res. 2017;77(14):3894-3907. doi:10.1158/0008-5472.CAN-17-0468

40. Ma Q, Long W, Xing C, et al. Cancer stem cells and immunosuppressive microenvironment in glioma. Front Immunol. 2018;9:2924. doi:10.3389/fimmu.2018.02924 
41. Ochs K, Sahm F, Opitz CA, et al. Immature mesenchymal stem celllike pericytes as mediators of immunosuppression in human malignant glioma. J Neuroimmunol. 2013;265(1-2):106-116. doi:10.1016/ j.jneuroim.2013.09.011

42. Sokratous G, Polyzoidis S, Ashkan K. Immune infiltration of tumor microenvironment following immunotherapy for glioblastoma multiforme. Hum Vaccin Immunother. 2017;13(11):2575-2582. doi:10.1080/ 21645515.2017.1303582

43. Becker JC, Andersen MH, Schrama D, Thor Straten P. Immune-suppressive properties of the tumor microenvironment. Cancer Immunol Immunother. 2013;62(7):1137-1148. doi:10.1007/s00262-013-1434-6

44. Renfrow JJ, Weller M, Strowd RE. Meeting update-world federation of neuro-oncology societies (WFNOS) meeting 2017. Neuro Oncol. 2017;19(11):1457-1459. doi:10.1093/neuonc/nox184

45. Filley AC, Henriquez M, Dey M. Recurrent glioma clinical trial, CheckMate-143: the game is not over yet. Oncotarget. 2017;8 (53):91779-91794. doi:10.18632/oncotarget.21586

46. Jiang H, Clise-Dwyer K, Ruisaard KE, et al. Delta-24-RGD oncolytic adenovirus elicits anti-glioma immunity in an immunocompetent mouse model. PLoS One. 2014;9(5):e97407. doi:10.1371/journal. pone.0097407

47. Kleijn A, Kloezeman J, Treffers-Westerlaken E, et al. The in vivo therapeutic efficacy of the oncolytic adenovirus Delta24-RGD is mediated by tumor-specific immunity. PLoS One. 2014;9(5):e97495. doi:10.1371/journal.pone.0097495

48. Kleijn A, Kloezeman J, Treffers-Westerlaken E, et al. The therapeutic efficacy of the oncolytic virus Delta24-RGD in a murine glioma model depends primarily on antitumor immunity. Oncoimmunology. 2014;3(9):e955697. doi:10.4161/21624011.2014.955697

49. van Den Bossche WBL, Kleijn A, Teunissen CE, et al. Oncolytic virotherapy in glioblastoma patients induces a tumor macrophage phenotypic shift leading to an altered glioblastoma microenvironment. Neuro Oncol. 2018;20(11):1494-1504. doi:10.1093/neuonc/ noy082

50. Kuryk L, Moller AW, Jaderberg M. Combination of immunogenic oncolytic adenovirus ONCOS-102 with anti-PD-1 pembrolizumab exhibits synergistic antitumor effect in humanized A2058 melanoma huNOG mouse model. Oncoimmunology. 2019;8(2):e1532763. doi:10.1080/ 2162402X.2018.1532763

51. Cervera-Carrascon V, Siurala M, Santos JM, et al. TNFa and IL-2 armed adenoviruses enable complete responses by anti-PD-1 checkpoint blockade. Oncoimmunology. 2018;7(5):e1412902. doi:10.1080/ 2162402X.2018.1490854

52. Woller N, Gurlevik E, Fleischmann-Mundt B, et al. Viral infection of tumors overcomes resistance to PD-1-immunotherapy by broadening neoantigenome-directed T-cell responses. Mol Ther. 2015;23 (10):1630-1640. doi:10.1038/mt.2015.115

53. Gea Z. Abstract - interim results of a phase II multicenter study of the conditionally replicative oncolytic adenovirus DNX-2401 with pembrolizumab(Keytruda) for recurrent glioblastoma; CAPTIVE STUDY (LEYNOTE-192). Neuro-Oncology. 2018;20(suppl_6):vi6. doi:10.1093/neuonc/noy148.019

54. Lang FF, Tran ND, Puduvalli VK, et al. Phase 1b open-label randomized study of the oncolytic adenovirus DNX-2401 administered with or without interferon gamma for recurrent glioblastoma. J Clin Oncol. 2017;35 (15_suppl):2002. doi:10.1200/JCO.2017.35.15_suppl.2002

55. Dunn J, Baborie A, Alam F, et al. Extent of MGMT promoter methylation correlates with outcome in glioblastomas given temozolomide and radiotherapy. $B r J$ Cancer. 2009;101(1):124-131. doi:10.1038/sj.bjc.6605127

56. Alonso MM, Gomez-Manzano C, Bekele BN, Yung WK, Fueyo J. Adenovirus-based strategies overcome temozolomide resistance by silencing the O6-methylguanine-DNA methyltransferase promoter. Cancer Res. 2007;67(24):11499-11504. doi:10.1158/0008-5472. CAN-07-5312
57. Kleijn A, van Den Bossche W, Haefner ES, et al. The sequence of delta24-RGD and TMZ administration in malignant glioma affects the role of $\mathrm{CD} 8(+) \mathrm{T}$ cell anti-tumor activity. Mol Ther Oncolytics. 2017;5:11-19. doi:10.1016/j.omto.2017.02.002

58. Wu G, Broniscer A, McEachron TA, et al. Somatic histone $\mathrm{H} 3$ alterations in pediatric diffuse intrinsic pontine gliomas and non-brainstem glioblastomas. Nat Genet. 2012;44(3):251-253. doi:10.1038/ng.1102

59. Wu G, Diaz AK, Paugh BS, et al. The genomic landscape of diffuse intrinsic pontine glioma and pediatric non-brainstem highgrade glioma. Nat Genet. 2014;46(5):444-450. doi:10.1038/ ng. 2938

60. Warren KE. Diffuse intrinsic pontine glioma: poised for progress. Front Oncol. 2012;2:205. doi:10.3389/fonc.2012.00205

61. Martinez-Velez N, Garcia-Moure M, Marigil M, et al. The oncolytic virus Delta-24-RGD elicits an antitumor effect in pediatric glioma and DIPG mouse models. Nat Commun. 2019;10(1):2235. doi:10.1038/s41467-019-10043-0

62. Martinez-Velez N, Marigil M, Garcia-Moure M, et al. Delta-24-RGD combined with radiotherapy exerts a potent antitumor effect in diffuse intrinsic pontine glioma and pediatric high grade glioma models. Acta Neuropathol Commun. 2019;7(1):64. doi:10.1186/s40478-0190714-6

63. Tejada S, Alonso M, Patino A, Fueyo J, Gomez-Manzano C, DiezValle R. Phase I trial of DNX-2401 for diffuse intrinsic pontine glioma newly diagnosed in pediatric patients. Neurosurgery. 2018;83(5):1050-1056. doi:10.1093/neuros/nyx507

64. Tejada S, Diez-Valle R, Dominguez PD, et al. DNX-2401, an oncolytic virus, for the treatment of newly diagnosed diffuse intrinsic pontine gliomas: a case report. Front Oncol. 2018;8:61. doi:10.3389/ fonc. 2018.00061

65. Aboody KS, Brown A, Rainov NG, et al. Neural stem cells display extensive tropism for pathology in adult brain: evidence from intracranial gliomas. Proc Natl Acad Sci U S A. 2000;97(23):1284612851. doi:10.1073/pnas.97.23.12846

66. Lesniak MS. Targeted therapy for malignant glioma: neural stem cells. Expert Rev Neurother. 2006;6(1):1-3. doi:10.1586/14737175.6.1.1

67. Martinez-Quintanilla J, Seah I, Chua M, Shah K. Oncolytic viruses: overcoming translational challenges. J Clin Invest. 2019;130:14071418. doi:10.1172/JCI122287

68. Yong RL, Shinojima N, Fueyo J, et al. Human bone marrow-derived mesenchymal stem cells for intravascular delivery of oncolytic adenovirus Delta24-RGD to human gliomas. Cancer Res. 2009;69 (23):8932-8940. doi:10.1158/0008-5472.CAN-08-3873

69. Sonabend AM, Ulasov IV, Tyler MA, Rivera AA, Mathis JM, Lesniak MS. Mesenchymal stem cells effectively deliver an oncolytic adenovirus to intracranial glioma. Stem Cells. 2008;26(3):831-841. doi:10.1634/stemcells.2007-0758

70. Ahmed AU, Thaci B, Tobias AL, et al. A preclinical evaluation of neural stem cell-based cell carrier for targeted antiglioma oncolytic virotherapy. $J$ Natl Cancer Inst. 2013;105(13):968-977. doi:10.1093/jnci/djt141

71. Tyler MA, Ulasov IV, Sonabend AM, et al. Neural stem cells target intracranial glioma to deliver an oncolytic adenovirus in vivo. Gene Ther. 2009;16(2):262-278. doi:10.1038/gt.2008.165

72. Kim CK, Ahmed AU, Auffinger B, et al. N-acetylcysteine amide augments the therapeutic effect of neural stem cell-based antiglioma oncolytic virotherapy. Mol Ther. 2013;21(11):2063-2073. doi: $10.1038 / \mathrm{mt} .2013 .179$

73. Ulasov IV, Rivera AA, Sonabend AM, et al. Comparative evaluation of survivin, midkine and CXCR4 promoters for transcriptional targeting of glioma gene therapy. Cancer Biol Ther. 2007;6(5):679-685. doi:10.4161/cbt.6.5.3957

74. Ulasov IV, Zhu ZB, Tyler MA, et al. Survivin-driven and fibermodified oncolytic adenovirus exhibits potent antitumor activity in established intracranial glioma. Hum Gene Ther. 2007;18(7):589602. doi:10.1089/hum.2007.002 
75. Ulasov IV, Rivera AA, Han Y, Curiel DT, Zhu ZB, Lesniak MS Targeting adenovirus to CD80 and CD86 receptors increases gene transfer efficiency to malignant glioma cells. J Neurosurg. 2007;107 (3):617-627. doi:10.3171/JNS-07/09/0617

76. Staba MJ, Wickham TJ, Kovesdi I, Hallahan DE. Modifications of the fiber in adenovirus vectors increase tropism for malignant glioma models. Cancer Gene Ther. 2000;7(1):13-19. doi:10.1038/sj.cgt.7700104

77. Zheng S, Ulasov IV, Han Y, Tyler MA, Zhu ZB, Lesniak MS. Fiberknob modifications enhance adenoviral tropism and gene transfer in malignant glioma. J Gene Med. 2007;9(3):151-160. doi:10.1002/ jgm. 1008

78. Perez-Cruet MJ, Trask TW, Chen SH, et al. Adenovirus-mediated gene therapy of experimental gliomas. J Neurosci Res. 1994;39 (4):506-511. doi:10.1002/jnr.490390417

79. Chen SH, Shine HD, Goodman JC, Grossman RG, Woo SL. Gene therapy for brain tumors: regression of experimental gliomas by adenovirus-mediated gene transfer in vivo. Proc Natl Acad Sci U S A. 1994;91(8):3054-3057. doi:10.1073/pnas.91.8.3054

80. Barba D, Hardin J, Sadelain M, Gage FH. Development of anti-tumor immunity following thymidine kinase-mediated killing of experimental brain tumors. Proc Natl Acad Sci U S A. 1994;91(10):4348-4352. doi:10.1073/pnas.91.10.4348

81. Trask TW, Trask RP, Aguilar-Cordova E, et al. Phase I study of adenoviral delivery of the HSV-tk gene and ganciclovir administration in patients with current malignant brain tumors. Mol Ther. 2000;1(2):195-203. doi:10.1006/mthe.2000.0030

82. Chiocca EA, Aguilar LK, Bell SD, et al. Phase IB study of genemediated cytotoxic immunotherapy adjuvant to up-front surgery and intensive timing radiation for malignant glioma. J Clin Oncol. 2011;29(27):3611-3619. doi:10.1200/JCO.2011.35.5222
83. Kieran MW, Goumnerova L, Manley P, et al. Phase I study of genemediated cytotoxic immunotherapy with AdV-tk as adjuvant to surgery and radiation for pediatric malignant glioma and recurrent ependymoma. Neuro Oncol. 2019;21(4):537-546. doi:10.1093/neuonc/noy202

84. Lowenstein PR, Castro MG. Evolutionary basis of a new gene- and immune-therapeutic approach for the treatment of malignant brain tumors: from mice to clinical trials for glioma patients. Clin Immunol. 2018;189:43-51. doi:10.1016/j.clim.2017.07.006

85. Desjardins A, Gromeier M, Herndon JE 2nd, et al. Recurrent glioblastoma treated with recombinant poliovirus. $N$ Engl J Med. 2018;379(2):150-161. doi:10.1056/NEJMoa1716435

86. Kim JW, Miska J, Young JS, et al. A comparative study of replication-incompetent and -competent adenoviral therapy-mediated immune response in a murine glioma model. Mol Ther Oncolytics. 2017;5:97-104. doi:10.1016/j.omto.2017.05.001

87. Yamamoto M, Curiel DT. Current issues and future directions of oncolytic adenoviruses. Mol Ther. 2010;18(2):243-250. doi:10.10 38/mt.2009.266

88. LaRocca CJ, Han J, Gavrikova T, et al. Oncolytic adenovirus expressing interferon alpha in a syngeneic Syrian hamster model for the treatment of pancreatic cancer. Surgery. 2015;157(5):888-898. doi:10.1016/j.surg.2015.01.006

89. Koodie L, Robertson MG, Chandrashekar M, et al. Rodents versus pig model for assessing the performance of serotype chimeric Ad5/3 oncolytic adenoviruses. Cancers (Basel). 2019;11(2):198. doi:10.3390/ cancers 11020198

90. Kuryk L, Moller AW, Jaderberg M. Abscopal effect when combining oncolytic adenovirus and checkpoint inhibitor in a humanized NOG mouse model of melanoma. J Med Virol. 2019;91(9):1702-1706. doi:10.1002/jmv.25501
Oncolytic Virotherapy

\section{Publish your work in this journal}

Oncolytic Virotherapy is an international, peer-reviewed, open access online journal publishing original research, study protocols, reviews, editorials and commentaries on all aspects of oncolytic virology, namely the application of oncolytic viruses for the treatment of cancer. Specific topics in the journal include: Rationale and theoretical aspects of oncolytic virotherapy including in vitro, in vivo and mathematical

Submit your manuscript here: http://www.dovepress.com/oncolytic-virotherapy-journal modeling; and practical application and problem solving in the clinic including identification of potential responders through biomarkers and genetic profiling. The manuscript management system is completely online and includes a very quick and fair peer-review system, which is all easy to use. Visit http://www.dovepress.com/ testimonials.php to read real quotes from published authors. 